\title{
Optimal Decision Making Method for Multi Criteria Problems
}

\author{
Roghayeh Zamani and Pirayeh Yousefi
}

\begin{abstract}
Decision making is one of the essential and important fieldsnowadays, by integrating decision making on multi criteria and fuzzy logic, there will be a satisfactory theoretical framework for system evaluation. There exist several methods for multi parametric decision making. In this paper we will introduce a new way and optimal method for multi parametric problems by taking Fuzzy AHP method into consideration. In this method, it is planned to calculate the weight of criteria by the help of AHP analytical steps. Then we will identify the best alternative by the help of the proposed method.
\end{abstract}

Index Terms-Multi criteria decision making (MCDM), AHP, fuzzy AHP.

\section{INTRODUCTION}

Optimal models are of great importance in decision making and there are employed in significant industrial issues. Multi criteria decision making has been introduced as one of the best methods in 1970. In recent years researchers have become interested in multi criteria decision making models. In this kind of decision making, instead of using a single method for evaluating Optimacy, they employ multiple criteria. Fuzzy set theory introduces an optimal method for decision making in MCDM issues to obviate complexity in human manner of think.

There are several ways for MCDM that one of which is AHP. This method is introduced by Saaty in 1980 for the first time. AHP is a method for ranking the alternatives in order to select the best one in case of having multiple criteria. In AHP, selecting between alternatives is carried out by the help of intelligent comparison. In a conscious comparison, the decision maker compares both of the solutions by taking one criteria into consideration. AHP is a method that is suitable for complicated systems and selects one option among all. AHP is established on considering a problem based on hierarchical order and lets analysts to consider different dimensions of the problem in a hierarchical structure like a tree, so it can converts complicated decision making to simple comparison and rankling to reach logical results [1], [2].

In AHP we should consider the qualitative and quantitative aspects of the issue.

In this method, the problem is considered in a hierarchical order and in this classification, the aim is at the top; the criteria are in middle and the alternatives are at the end of the

Manuscript received February 7, 2013; revised July 16, 2013.

Roghayeh Zamani is with Bostanabad branch, Islamic Azad University, Bostanabad, Iran (e-mail: r_zamani84@yahoo.com).

Pirayeh Yousefi is with Marand branch, Islamic Azad University, Marand, Iran (e-mail: pi_yousefi@marandiau.ac.ir). hierarchy [3]-[5].

Here all of the components are compared with there counterpart criterias. The analytic method tries to calculate index vectors until the final common coeffiecent verctor is determined for all of the alternatives. The inputs of the final weight coeffiecent vectors, is the value of every alternative for every goal which is placed at the top of the hierarchy [2], [5].

In sum, the steps employed in AHP, are as followings:

1) Specifying the decision making criterion like a goal hierarchy. This hieararchy has different levels in which, the goal is on the top, criteria and subcriteria are in middle and the alternatives are in the down.

2) It evaluate the weigth of the criteria and subcriteria and alternatives, as a function of their importance, which shows there importance for the upper element. For achive this goal, AHP does simple peer to peer comparisons, to specify the weigths and the analysist can focus on two factor at the same time.

3) After expanding the comparison matrix, a priority vector for getting the weigth of matrix elements can be calculated. This index vector is the normalized version of the matrix.

We use AHP instead of multi criteria techniques because:

1) The quality and quantity criteria are considered in decision making.

2) Many of the criterias are taking into consideration.

3) A flexible hierarchy which is accommodiate to the problem is built.

In this paper, Section II refers to review of fuzzy AHP, Section III explains the proposed method, Section IV represents numerical example and the last section represents the conclusion.

\section{FUZZY AHP}

In order to cooperating of ambugity of human reflection, Zadeh represented the theory of fuzzy set that tended to raltionalism, incertitude because of ambiquity and inaccuracy. One of current problem in fuzzy set theory is it's potency in representing of ambiguous data. This theory allows mathematical users to plan for using of fuzzy domain. The fuzzy set is a group of variants that have membership continuum. This set is determined by the help of the parametric membership functionality, which it assigns a degree of membership between 0,1 to each of them. The symbol " " on top of the function, represents the fuzzy set. Therefore, $\breve{a}, \tilde{p}$ and $\breve{m}$ are all of fuzzy group.

The membership performance of these groups designed by $\mu(x \mid \tilde{p})$. Fig. 1 represents a triangular figure (TFN). 
The TFN determined as $\left(\frac{m_{1}}{m_{2}}, \frac{m_{2}}{m_{3}}\right)$ or $\left(m_{1}, m_{2}, m_{3}\right)$. The parameters of $m_{3}, m_{2}, m_{1}$ is smallest, middle and largest possible value repeectivity. The possible largest value is determined of a fuzzy event.

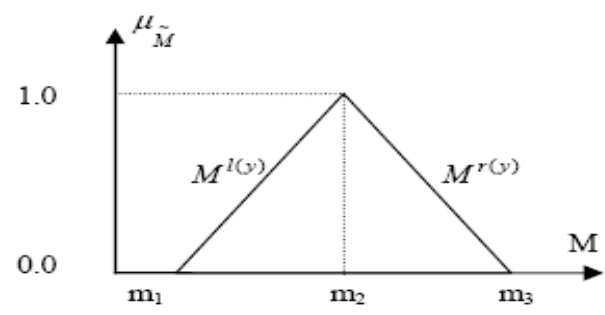

Fig. 1. TFN numbers (trianguilar fuzzy numbers).

The fuzzy AHP is an extended version of AHP that makes the data fuzziness possible. Understanding of the fuzzy AHP is easy and management of the quality and quantity of data in multi data decision making is easy [3], [5].

In AHP steps the result of peer to peer comparisons in final matrix are fuzzy numbers that are explained by the designer.

\section{The New Method of FuZZY Multi CREITERIA DECISION MAKING}

In this method we use triangular fuzzy number. To calculate the weights of triangular numbers, we used buckly geometric average for quadruple numbers as well which is modified for fuzzy triangular numbers. At first, we organize the problemas hierachical structure and after determining the given levels, criteria and alternatives, obtain comparative analogy for any level with regard to top level goal. After calculation of matrix, the geometric mean any row of matrix was obtained and calculated based on them, the values of $w_{i}, w n_{i}$ for any matrix. Then we devide the sum of the achived weights and criteria by the sum of the sum of the weight achived for criteria. We determine the least value as the fuzzy number for that index. Then by using of (4), (5) we calculate $\mu\left(u_{i}\right)$ for any of numbers and select the optimal onewhich has extreme value among indexes, as the best alternative. The given algorithm phases includes:

1) We obtain the comparative anology matrix A from DM as $\tilde{x}=\left(a_{i j}, b_{i j}, c_{i j}\right)$.

2) We calculate geometric mean of any row:

$$
h_{i}=\left\{\tilde{x}_{i 1}(.) \tilde{x}_{i 2}(.) \ldots(.) \tilde{x}_{i n}\right\}^{\frac{1}{n}}
$$

where $\tilde{x}_{i j}$ is the index $I$ from fuzzy number for $j t h$ criteria, $h_{i}$ is ith index geometric mean.

3) We calculate the weights $w_{i}$ for any row of comparative matrix as follow :

$$
w_{i}=h_{i} / h_{1}(+) h_{2}(+) \ldots(+) h_{n}
$$

where $w_{i}$ is $i t h$ index weight for criteria matrix.

4) After calculatingthe weights for criteria matrix, we calculate $w n_{i j}$ weights by (1) and (2). $w n_{i j}$ is the weight of $i t h$ index for $j t h$ criteria for $j t h$ criteria.

5) We calculate the $u_{i}$ values by using (3) after measuring of $w n_{i j}, w_{i}$ weights.

$$
\forall i \in m u_{i}=\min _{j=1}^{n}\left(\left(w n_{i j}+w_{j}\right) / \sum_{j=1}^{n} w_{j}\right)
$$

where $u_{i}$ is obtained fuzzy number for any alternative.

6) We calculate the $\mu\left(u_{i}\right)$ value by (4) for alternatives after obtaining $u_{i}$ and select the best alternative from obtained value:

$$
\begin{gathered}
\mu\left(u_{i}\right)=\min \left(s_{i, j}\right) \\
S_{i, j}=\left(2 * u_{i} \cdot u_{j}\right) /\left(u_{i}+u_{j}\right)^{\wedge} 2-\left(u_{i} \cdot u_{j}\right)
\end{gathered}
$$

where $S_{i, j}$ is the it'h fuzzy number to $\mathrm{j}$ fuzzy number and $\mu\left(u_{i}\right)$ is obtained mathematical value for any alternative.

We select the extreme value as the most proper alternative after calculation of given value. We rate the alternatives by $\mu\left(u_{i}\right)$ values. In the following, the mathematic example is given and the result of this method constrasted with two other method i'e fuzzy MCDM and topsis.

\section{EXAMPLE}

Use either A director is going to select most proper project for conducting with regard to given criteria. The criteria include: Net Present Value (NPV), Capital Return Rate (ROR), Benfit Charge (BC), PayBack date (PB). Now, we are going to select the proper one of six available projects for conducting with regard to his criteria [4].

By using of given method, the first step is forming rated structure and making decision matrix for criteria and alternatives. The Tables I and II represent the criteria matrix for criteria and indexes matrix for one of criteria (ROR). We calculate the weights for any of them after forming matrix by (1).

$$
\begin{aligned}
& w_{1}=(.1525, .2856, .4826) \\
& w_{2}=(.0794, .1580, .3052) \\
& w_{3}=(.1789, .3396, .6555) \\
& w_{4}=(.1662, .2168, .4188) \\
& w n_{1,1}=(.0572, .2853,3.0207) \\
& w n_{1,2}=(.0485, .08000, .9010) \\
& w n_{1,3}=(0, .05990, .4213) \\
& w n_{1,4}=(0, .1763,17.9248)
\end{aligned}
$$

The given calculations are mentioned for two matrixes. For 
other matrixes, we calculate $w n_{i, j}$ values as same way. Now, we calculate the $u_{i}$ values for each alternative by 3 and $\mu\left(u_{i}\right)$ values for all of alternatives that, has been recorded on Table III.

As has been seen in given table, the project6 has extreame value and is the best select for him. The priortiyizing of the alternativesas follows:

$$
P_{6}>P_{3}>P_{2}>P_{1}>P_{4}>P_{5}
$$

The given example was calculated by fuzzy MCDM and TOPSIS that is one of the mathematical methods in multiple decision making metho. Table IV shows the results of our experiments.

Fig. 2 represents the normalized decision numbers for various alternatives by giving three methods. As seen in Fig. 2 at any of these methods, P6 has been selected as the best alternative and the prority of alternatives is as follows:

The new method: $P 6>P 2>P 1>P 3>P 4>P 5$

\section{TOPSIS: $P 6>P 5>P 3>P 2>P 4>P 1$}

\section{MCDMFuzzy: $P 6>P 2>P 3>P 1>P 4>P 5$}

If we compare the proposed method with MCDM, we see that they have more accomodation about giving the priority to alternatives. So according to AHP's advantages and its efficiency in the problems, our proposed method is appropreate and simple.

TABLE I: CRITERIA COMPARE MATRIX

\begin{tabular}{|c|c|c|c|c|}
\hline & ROR & PB & NPV & CB \\
\hline $\boldsymbol{R O} \boldsymbol{R}$ & $(1,1,1)$ & $(1,2,3)$ & $(.75,1,1.25)$ & $(.75,1,1.25)$ \\
\hline $\boldsymbol{P B}$ & $(.33, .5,1)$ & $(1,1,1)$ & $(.25, .5, .75)$ & $(.5, .75,1)$ \\
\hline $\boldsymbol{N P V}$ & $(.8,1,1.33)$ & $(1.33,2,4)$ & $(1,1,1)$ & $(1,2,3)$ \\
\hline $\boldsymbol{B C}$ & $(.8,1,1.33)$ & $(1,1.33,2)$ & $(.33, .5,1)$ & $(1,1,1)$ \\
\hline
\end{tabular}

TABLE II: COMPARE MATRIX FOR ROR

\begin{tabular}{|c|c|c|c|c|c|c|}
\hline ROR & P1 & P2 & P3 & P4 & P5 & P6 \\
\hline$P 1$ & $(1,1,1)$ & $\begin{array}{l}(.0285, \\
.2785, \\
.5285)\end{array}$ & $\begin{array}{c}(.7072 \\
, .9572 \\
1.2072)\end{array}$ & $\begin{array}{c}(.5422, \\
.7922, \\
1.0422)\end{array}$ & $\begin{array}{l}(.2587, \\
.6787, \\
.9287)\end{array}$ & $\begin{array}{l}(.456, \\
.7060, \\
.956)\end{array}$ \\
\hline$P 2$ & $\begin{array}{c}(.6585, \\
.9085 \\
, 1.1585)\end{array}$ & $(1,1,1)$ & $\begin{array}{l}(.2354, \\
.4854, \\
.7354)\end{array}$ & $\begin{array}{l}(.7095, \\
.09595, \\
1.2095)\end{array}$ & $\begin{array}{c}(.5077, \\
.7577, \\
1.0077)\end{array}$ & $\begin{array}{c}(0, \\
.0318, \\
.0636)\end{array}$ \\
\hline$P 3$ & $\begin{array}{l}(.027 \\
, .1270 \\
, .227)\end{array}$ & $\begin{array}{c}(.7075, \\
.9575 \\
, 1.2075)\end{array}$ & $(1,1,1)$ & $\begin{array}{c}(.4057, \\
.6557, \\
.9057)\end{array}$ & $\begin{array}{c}(.4931, \\
.7431 \\
.9931)\end{array}$ & $\begin{array}{l}(.0269, \\
.2769, \\
.5269)\end{array}$ \\
\hline$P 4$ & $\begin{array}{c}(.6634, \\
.9134, \\
1.1634)\end{array}$ & $\begin{array}{c}(.7149, \\
.9649 \\
, 1.1249)\end{array}$ & $\begin{array}{l}(.0419, \\
.1419, \\
.2419)\end{array}$ & $(1,1,1)$ & $\begin{array}{l}(.1422, \\
.3922, \\
.6422)\end{array}$ & $\begin{array}{c}(0, \\
.0462, \\
.0924)\end{array}$ \\
\hline$P 5$ & $\begin{array}{l}(.3824 \\
, .6324, \\
.8824)\end{array}$ & $\begin{array}{l}(.0576, \\
.1576 \\
.2576)\end{array}$ & $\begin{array}{l}(.1718, \\
.4218, \\
.6718)\end{array}$ & $\begin{array}{c}(.5991, \\
.8491, \\
1.0991)\end{array}$ & $(1,1,1)$ & $\begin{array}{c}(0, \\
.0971, \\
.1942)\end{array}$ \\
\hline$P 6$ & $\begin{array}{c}(0, \\
.0975, \\
.195)\end{array}$ & $\begin{array}{c}(.7206 \\
.9706 \\
, 1.2206)\end{array}$ & $\begin{array}{c}(.6657, \\
.9157, \\
1.1657)\end{array}$ & $\begin{array}{l}(.144, \\
.3940, \\
.644)\end{array}$ & $\begin{array}{l}(.0712, \\
.1712, \\
.2712)\end{array}$ & $(1,1,1)$ \\
\hline
\end{tabular}

TABLE III: THE NORMALIZED VALUE OF FINAL SCORE OF PRESENTED

\begin{tabular}{|c|c|c|c|}
\hline & New method & fuzzy MCDM & TOPSIS \\
\hline $\boldsymbol{P 1}$ & 0.68444 & .5444 & .378043 \\
\hline $\boldsymbol{P 2}$ & 0.75605 & .5901 & .496176 \\
\hline $\boldsymbol{P 3}$ & 0.7857 & .5773 & .538381 \\
\hline $\boldsymbol{P 4}$ & 0.6450 & .4780 & .438027 \\
\hline $\boldsymbol{P 5}$ & 0.63957 & .4634 & .54468 \\
\hline $\boldsymbol{P 6}$ & 0.85501 & .6029 & .604535 \\
\hline
\end{tabular}

TABLE IV: THE NORMALIZED VALUE OF FINAL SCORES OF METHODS

\begin{tabular}{|c|c|}
\hline alternative & score \\
\hline Project1 & 0.68444 \\
\hline Project2 & 0.75605 \\
\hline Project3 & 0.7857 \\
\hline Project4 & 0.6450 \\
\hline Project5 & 0.63957 \\
\hline Project6 & 0.85501 \\
\hline
\end{tabular}

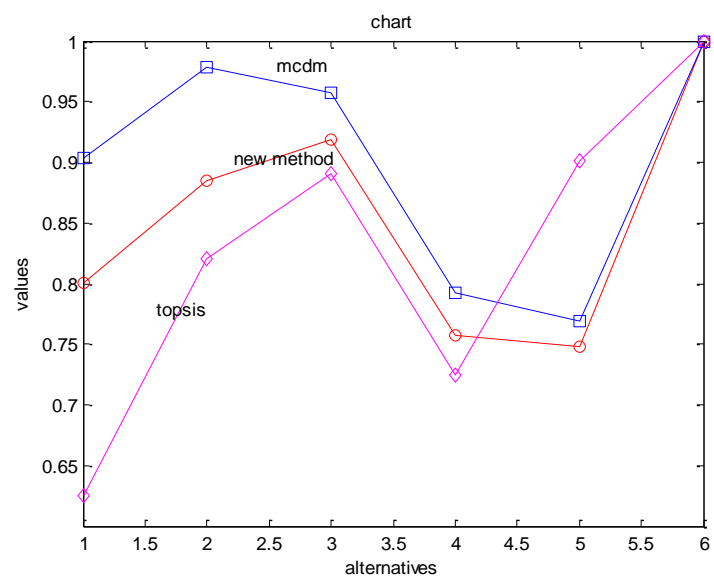

Fig. 2. Normalized value of three methods.

\section{CONCLUSION}

In this paper, a new method is proposed based on fuzzy AHP Method in which, the numbers and data is as triangular fuzzy numbers. The advantage of this algorithm is that, it is applicable for any types of MCDM problems. This method is reasonable for MODM problems that in them, there isn't available occurate decision matrix, and has agreeable application for problems that, criteria is multi layer or is used of several DM for decision making. The other advantage of it, related to simplicity of calculation and low action time that could be has reasonable application in real time systems. The obtained results of given method was contrasted with MCDM and Topsis. The results indicate that, it could be applied in fast calculations in real time problems.

\section{REFERENCES}

[1] C. C. Chou, "A fuzzy multiple critera decision making method," Taiwan, Republic of China, presented at the IEEE 2006, Colombia, 2006 . 
[2] L. A. Marks, E. G. Dunn, J. M. Keller, and L. D. Godsey, "Multiple Criteria Decision Making (MCDM) using fuzzy logic: an innovative approach to sustainable agriculture," in Proc. 3rd International Symposium on Uncertainty Modelling and Analysis (ISUMA), 1995, pp. 503.

[3] C. Zhang, X. M. Song, and W. Li, "A model combined fuzzy optimum theory with analytical hierarchy process for engineering design," in Proc. IEEE Trance, Fourth International Conf. on Fuzzy Systems and Knowledge Discovery, FSKD, 2007.

[4] S. Mahmoodzadeh, J. Shahrabi, M. Pariazar, and M. S. Zaeri, "Project selection by using fuzzy AHP and topsis technique," in Proc. IEEE Trance on 5th Spring Conf, 2005.

[5] A. Özdağoğlu and G. Özdağoğlu, "Comparison of AHP and fuzzy AHP for the multicriteria decision making processes with linguistic evaluations," İstanbul Ticaret Üniversitesi Fen Bilimleri Dergisi Y1l, pp. 65-85, Jan. 2007.

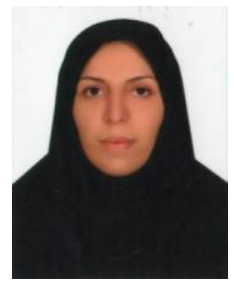

Roghayeh Zamani was born in Tabriz of Iran at 1982. She obtained the M.A. of software engineering from Azad University branch of Tabriz. She started her work at 2005 in Azad University as a professor. She has four formal article essays that presented in international and national conferences, also she has six accepted essays in local conferences. 